\title{
Measures of volatility for the Romanian Stock Exchange: a regime switching approach
}

\author{
Iulian-Cornel LOLEA \\ The Bucharest University of Economic Studies, Bucharest, Romania \\ loleaiulian@gmail.com \\ Lucian Constantin VILCU \\ The Bucharest University of Economic Studies, Bucharest, Romania \\ vilcu.constantin.lucian@gmail.com
}

\begin{abstract}
This paper aims to identify if regime-switching GARCH models perform better than singlestate GARCH models for the Romanian stock market. There will be used two approaches: in-sample and out-of-sample. All estimations are going to be made for the BET Index, which is the most relevant index from the selected market. The results will be ranked based on statistical loss functions for each of the two considered approaches. These rankings should ensure an accurate comparison for models' performance and they succeeded to return about the same results as in the relevant literature. Hence, for the in-sample evaluation there was no model which performs best for all loss-functions, but one can notice that for the out-of-sample evaluation the regime-switching models performed better especially on short-term (1-day observation period). All of these results were used further to improve some risk management strategies based on VaR, for which the volatility could be estimated through regimeswitching GARCH models, than considering historical volatility.
\end{abstract}

Keywords: volatility, BET Index, stock exchange, VaR, loss functions, performance evaluation.

\section{Introduction}

Financial markets volatility is one of the most discussed topics by researchers interested in field of asset pricing and risk management. Hence, there were various papers in the last decades that focus on measuring and forecasting volatility and a lot of models have been developed in this way.

Volatility forecasting is a complex process for which a variety of models have been developed. Hence, through this paper we aim to apply some of the most innovative models for estimating volatility for the Romanian stock market. The literature is not very rich in the analysis of volatility on the Romanian stock market, much less when we are talking about the application of state-dependent GARCH models for the forecasting volatility.

Thus, one of the novelties brought by this paper would be the application of innovative models for estimating stock market volatility for the Romanian market. These models will also be used to calculate VaR (value-at-risk) for the BET Index for the out-ofsample, which is also a way to test and rank them based on risk management functions.

Our research is closely related to the one of Klaassen (2002), Marcucci (2005), and Patton (2011). This paper distinguishes from the above mentioned ones by bringing evidence from CEE countries instead on focusing on the U.S. Furthermore, our results for CEE markets are quite different from the ones reported for U.S., which suggests that further research is needed to determine the added value of regime-switching GARCH models.

This paper is going to be organized as follows: Introduction, Literature Review, Methodology, Results and Conclusion. The first part, the introduction, presents the main 
idea that is going to be developed in this paper and it tries to help the reader in his way of understanding how the paper is organized. Further, Literature Review, makes a brief incursion in what was written until now on this subject.

The chapter related to methodology is probably the most important because it presents how the research was done and how to read the results. As it was earlier stated, this paper aims to evaluate the performance of different GARCH models in-sample and outof-sample using statistical loss functions and risk management functions. In last two chapters we summarized the results obtained and we tried to put them into the actual context on the capital markets.

Forecast evaluation is a key step in any forecasting exercise. Granger and Poon's (2003) statement "the success of a volatility model lies in its out-of-sample forecastingpower" clearly underlines the fact that the main use of a volatility model is volatility forecasting and that the performance should be addressed in relation to forecast accuracy. There are several methods of evaluating the accuracy of forecasts. Some of them are statistical loss functions, tests of directional predictive ability tests of equal and superior predictive ability.

\section{Literature review}

A short brief of the literature should begin with ARCH models presented by Engle (1982). This research was followed by Bollerslev, Chou and Kroner (1992) which summarized all articles related to this topic. The most important contribution related to volatility modelling was brought by the family of GARCH models. These models assume that volatility is timevarying and is considered to be influenced by both, the past volatility and innovations. Moving a step further we get closer to the most recent improvement regarding the GARCH models: Regime-Switching GARCH. This extension of GARCH models is expected to bring more accurate forecasts because of its flexibility regarding the persistence of volatility.

Our research is closely related to the one of Klaassen (2002), Marcucci (2005), and Patton (2011). This paper distinguishes from the above mentioned ones by bringing evidence from CEE countries instead on focusing on the U.S. Furthermore, our results for CEE markets are quite different from the ones reported for U.S., which suggests that further research is needed to determine the added value of regime-switching GARCH models.

Taking the research of Engle (1982) to a next level, Taylor (1986) and Bollerslev developed the GARCH(p,q) model, where they considered in addition q lags from the past conditional variance. GARCH $(p, q)$ offers flexibility for taking into account, both autoregressive and moving average components, in the equation of variance.

Further, after the development of GARCH models in the last decade, there were a lot of extensions that have been introduced in order to solve some of the GARCH models' problems. Considering that the classical GARCH models were symmetric models, they were unable to account for the leverage effect from series of stock return observed in capital markets, many researchers proposed some asymmetric GARCH models to solve this problem. So did the EGARCH (exponential GARCH) appeared, proposed by Nelson (1991) to solve the lack of ability of GARCH models to take into consideration the leverage effect on financial markets. Furthermore, Glosten, Jagannathan and Runkle (1993) proposed the GJRGARCH model (asymmetric model) that allows for different responses of the conditional variance in different ways to positive or to negative shocks. 
The research regarding volatility modelling was continued through incorporating regimes or states into GARCH models, which makes it state dependent. Thus, how quick the variance will get to the long-run average will be state-dependent. So, a multi-state model should be more flexible than a single-state model. Hence, including regimes in a GARCH model may yield better estimation of volatility and could bring value added.

A first way of modelling volatility persistence could be considered using the approach proposed by Hamilton (1989), a regime-switching mode. This concept was further applied and developed in different papers, such as those of Pagan \& Schwert (1990) or Hamilton\&Susmel (1994), but these models tend to be rigid and they do not incorporate very well the idea of state-dependent volatility.

The above presented models were extended by Gray (1996) and Klaassen (2002), taking into consideration that the volatility could vary between two states (low volatility regime and high volatility regime) and the probability of being in each state could be also time dependent. This was thought to be a better way to take into consideration the leverage effect and the results revealed that the new models performed better in terms of volatility forecasting.

\section{Methodology}

The methodology used in this paper is in accordance with the ones presented in the literature and it will be divided into three sections: description of GARCH models (singlestate models), description of Markov-Switching Models (MRS-GARCH) and the methodology based on which we will do the forecasting evaluation (volatility proxies, risk-management functions and statistical loss-functions).

\section{Classical models for forecasting volatility}

The first model that should be presented is the general GARCH $(p, q)$

$\operatorname{GARCH}(p, q)$

$$
h_{t}^{2}=\alpha_{0}+\sum_{i=1}^{q} \alpha_{i} * \varepsilon_{t-i}^{2}+\sum_{j=1}^{p} \beta_{j} * h_{t-j}^{2}
$$

Conditional mean

$$
r_{t}=a+\eta_{t} h_{t}
$$

where $\eta_{t}$ i.i.d

GARCH $(1,1)$

$$
h_{t}^{2}=\alpha_{0}+\alpha_{1} \varepsilon_{t-1}^{2}+\beta_{1} h_{t-1}^{2}
$$

with the following parameter constraints: $\alpha_{0} \geq 0 ; \alpha_{1} \geq 0 ; \beta_{1} \geq 0$, which ensures that we will obtain an estimated positive conditional variance.

EGARCH $(1,1)$

$$
\log \left(h_{t}^{2}\right)=\alpha_{0}+\alpha_{1}\left|\frac{\varepsilon_{t-1}}{h_{t-1}}\right|+\xi\left(\frac{\varepsilon_{t-1}}{h_{t-1}}\right)+\beta_{1} \log \left(h_{t-1}^{2}\right)
$$

The next model considered in this paper is the one developed by Glosten, Jagannathan and Runkle (1993) which tried to better take into consideration the leverage effect (GJRGARCH model): 
GJR-GARCH $(1,1)$

$$
h_{t}^{2}=\alpha_{0}+\alpha_{1} \varepsilon_{t-1}^{2}\left[1-I_{\left\{\varepsilon_{t-1>0\}}\right.}\right]+\xi \varepsilon_{t-1}^{2} I_{\left\{\varepsilon_{t-1>0\}}\right.}+\beta_{1} h_{t-1}^{2}
$$

Regime switching models (MRS-GARCH)

As it was presented above, previous models assumed asymmetry in volatility paths, but Hamilton and Susmel (1994) introduced the idea that volatility could be modelled as a regime-switching process. In their paper, they assumed that the jumps in volatility could be captured trough switches between the regression. So, it was introduced a discrete state variable $s_{t}$ which is considered to follow an ith order Markov-chain. This means that $s_{t}$ is supposed to be dependent only on the ith previous states. This is a short definition of a Markov-Chain.

Hamilton and Susmel's approach became well-known in the literature, but it has its limitations, regarding the long lag structures. Hence, Gray (1996) and Klassen (2002) improved the approach brought in the literature by Hamilton and Susmel. They tried to solve in some manner the problem of making the model intractable and they suggested several estimation techniques. This kind of approach is going to be used also in this paper.

According to the above presented theory, MRS-GARCH assumes that a state variable exists, which is going to evolve according to a first-order Markov Chain with the transition probabilities defined as follows:

$$
\operatorname{Pr}\left(s_{t}=j \mid s_{t-1}=i\right)=p_{i, j}
$$

The state variable $s_{t}$ gives the probability of switching from state i at time t- 1 into state $j$ at time $t$, which taken together could form the transition matrix (7). This matrix is based on a 2-state Markov-Chain like it is presented below in figure 1.

Figure 1. Two state volatility Markov Chain

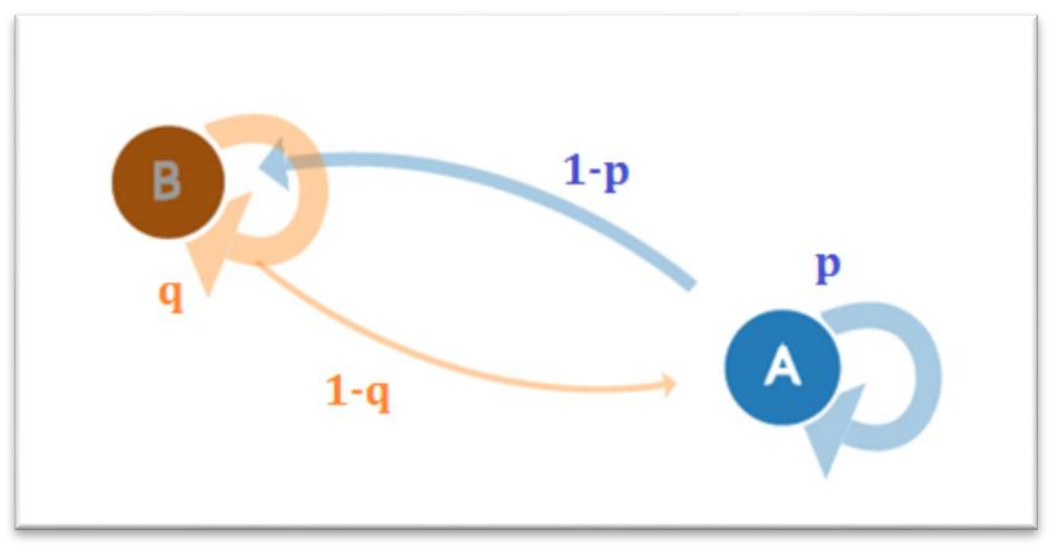

$$
P=\left(\begin{array}{ll}
p_{11} & p_{21} \\
p_{12} & p_{22}
\end{array}\right)=\left(\begin{array}{cc}
p & (1-q) \\
(1-p) & q
\end{array}\right)
$$

Source: Authors' own computation.

If

A = Low volatility state $\left(s_{t}=1\right)$

$\mathrm{B}=$ High volatility state $\left(s_{t}=2\right)$

Then the unconditional probability (ergodic probability) of $s_{t}=1$ is captured by $\pi_{1}=\frac{(1-q)}{(2-p-q)}$. 


\section{Evaluation of the forecasting performances}

In this paper there will be two types of forecasts: one-step ahead volatility forecast and hstep ahead volatility forecasts. The first one is obtained based only on the present time period as in the following example of GARCH $(1,1)$ :

$$
\hat{h}_{t+1}^{2}=\alpha_{0}+\alpha_{1}+\beta_{1} h_{t}^{2}
$$

Furthermore, we are going to use in our approach the h-step ahead volatility forecast presented as $\hat{h}_{t+h \mid t}^{2}$. This measure of volatility is computed based on the aggregated forecasts for the next " $h$ " steps calculated at time " $\mathrm{t}$ ", i.e. $\hat{h}_{t+h \mid t}=\sum_{j=1}^{h} \hat{h}_{t+j \mid t}$. We will obtain volatility forecasts for horizons of 1,5 and 10-days by taking into consideration the aggregated volatility forecasts over the next 1,5 and 10 days.

We are going to use the following classical measure as a proxy for volatility when performing performance evaluation:

\section{Evaluation methods}

$$
R 2_{t}=\left(r_{t}-\frac{1}{n} \sum_{i=1}^{n} r_{i}\right)^{2}
$$

\section{Standard Statistical Loss Functions}

The forecasting performances of the models were evaluated based on statistical loss functions which are presented below. There literature does not present a loss functions which is the best in evaluating performance. Each of them has its drawbacks, but we could conclude that the model that performs best for most criteria is the most suited one.

$$
\begin{gathered}
M S E_{1}=n^{-1} \sum_{t=1}^{n}\left(\sigma_{t+1}-h_{t+1 \mid t}\right)^{2} \\
M S E_{2}=n^{-1} \sum_{t=1}^{n}\left(\sigma_{t+1}^{2}-h_{t+1 \mid t}{ }^{2}\right)^{2} \\
\text { QLIKE }=n^{-1} \sum_{t=1}^{n}\left(\log \left(h_{t+1 \mid t}{ }^{2}\right)+{\sigma_{t+1}}^{2} h_{t+1 \mid t}{ }^{-2}\right) \\
R 2 L O G=n^{-1} \sum_{t=1}^{n}\left(\log \left(\mathrm{h}_{\mathrm{t}+1 \mid \mathrm{t}}^{2} \sigma_{\mathrm{t}+1}^{2}\right)\right)^{2} \\
M A D_{1}=n^{-1} \sum_{t=1}^{n}\left|\sigma_{t+1}-h_{t+1 \mid t}\right| \\
M A D_{2}=n^{-1} \sum_{t=1}^{n}\left|\sigma_{t+1}^{2}-h_{t+1 \mid t}^{2}\right| \\
H M S E=T^{-1} \sum_{t=1}^{T}\left(\sigma_{t+1}^{2} h_{t+1 \mid t}^{2}-1\right)^{2}
\end{gathered}
$$

Intuitively, the loss functions reveal us information about how reasonable the performances of the models were. The decision is simple: the model which obtain the smallest value of the loss functions is the one that performed the best. Although, different models could perform best at different statistical loss functions, we should make a rank taking into consideration all obtained results. 


\section{Risk management loss functions}

This research paper will conclude with a last way of comparing the models' performance using risk management loss functions. It is easy to see why this approach has been chosen, especially in the current context where emphasis is placed on risk management, due to the recent turmoil in financial markets. During the 2008 crisis, it was proven that the VaR (Value at Risk) risk measure was not good enough, resulting in losses much higher than the expectations of portfolio managers. Those type of VaRs were constructed based on historical volatility or at least based on a volatility modeled with GARCH using a normal distribution. Hence, the decision to include this kind of approach was based on all these recent developments and the research published by Brooks and Persand (2003), in which they proposed the use of VaR-based loss functions for the ranking of GARCH models. The way this approach is going to be used will be presented below, starting with the definition of VaR for a model in general form:

VaR at the time " $\mathrm{t}$ " for the model " $\mathrm{i}$ " with $\alpha \%$ degree of confidence :

$$
\operatorname{VaR}_{t}^{i}=\mu_{t+n}^{i}+\phi(\alpha) \sqrt{h_{t+n}^{i}}
$$

Where $\phi(\cdot)$ is the distribton function and " $n$ " is the investment horizon; in this research paper we will have $\mathrm{n}=1,5,10$ days

$\alpha=5 \%$,

$\mu_{\mathrm{t}+\mathrm{n}}^{\mathrm{i}}$ - the conditional mean used in VaR

$\mathrm{h}_{\mathrm{t}+\mathrm{n}}^{\mathrm{i}}$ is the forecasted volatility for model "i".

Based on the VaR series we will apply some test that are going to bring into light some conclusions regarding how the models performed. The TUFF test (Time Until First Failure) represents the number of observations until the VaR was first surpassed by the real loss occurred on the market. The null hypothesis reveals that $H_{0}: \alpha=\alpha_{0}$ and the alternative hyphothesis reveals that there is a significant difference between the two steps. Further, there could be applied the LR test (Loss ratio test), which has the following form:

$$
\operatorname{LR}_{\mathrm{TUFF}}(\widehat{\mathrm{T}}, \widehat{\alpha})=-2 \log \left\{\widehat{\alpha}(1-\widehat{\alpha})^{\widehat{\mathrm{T}}-1}\right\}+2 \log \left\{\frac{1}{\widehat{\mathrm{T}}}\left(1-\frac{1}{\widehat{\mathrm{T}}}\right)^{\widehat{\mathrm{T}}-1}\right\}
$$

where $\widehat{T}$ represents the number of observations until first failure. $L_{\mathrm{TUFF}}$ is asymptotically distributed to $\mathrm{X}^{2}(1)$.

\section{The data}

Firstly, we will have to describe the data series that are going to be used: daily data (closing prices) for the Romanian stock index BET in the period between 1st of January 2006 and 31st of October 2017. These series will be modelled according to the methodology proposed by Marucucci (2005). From the series of daily prices we will obtain new series of returns according to the formula:

$$
r_{t}=100\left(\log \left(p_{t}\right)-\log \left(p_{t-1}\right)\right)
$$

The period of time for which the data was used was 01/01/2006 - 31/10/2017.Thus, we will have series for BET Index composed out of 2930 observations. Furthermore, these series had to be subdivided into two subintervals to enable the two types of analysis that are going to be implemented, in-sample and out-of-sample. The two subintervals are going to be constructed as follows: 
BET Index : 150 observations for out-of-sample and 2780 observations for in-sample

\section{Results and discussions}

As we said before, there will be computed estimations for the most relevant stock exchange index from Romania: BET INDEX. The following models are going to be estimated GARCH, EGARCH, GJR-GARCH and MRS-GARCH using three types of distributions for models' errors: Normal distribution, Student distribution and GED distribution. Also, there will be an insample and an out-of-sample analysis for each model. The estimated parameters for the Romania stock exchange market, using single state GARCH models are presented in the following table:

Table 1. Parameters estimated for single-state GARCH models

\begin{tabular}{|c|c|c|c|c|c|c|c|c|c|}
\hline Parameters & GARCH & $\begin{array}{c}\text { GARCH- } \\
\mathrm{t} \\
\end{array}$ & $\begin{array}{l}\text { GARCH- } \\
\text { GED } \\
\end{array}$ & EGARCH & $\begin{array}{c}\text { EGARCH- } \\
\mathrm{t} \\
\end{array}$ & $\begin{array}{l}\text { EGARCH- } \\
\text { GED }\end{array}$ & $\begin{array}{l}\text { GJR- } \\
\text { GARCH } \\
\end{array}$ & $\begin{array}{c}\text { GJR- } \\
\text { GARCH- } \\
t \\
\end{array}$ & $\begin{array}{c}\text { GJR- } \\
\text { GARCH- } \\
\text { GED } \\
\end{array}$ \\
\hline$\delta$ & 0.0711 & 0.0802 & 0.0718 & 0.0623 & 0.0729 & 0.0644 & 0.062 & 0.0727 & 0.0648 \\
\hline t-Stat & 3.26 & 3.94 & 3.72 & 2.94 & 3.68 & 3.39 & $1.66^{*}$ & 3.54 & 3.32 \\
\hline$\alpha(0)$ & 0.623 & 0.0666 & 0.0691 & $(0.20)$ & -0.162 & -0.1817 & 0.0784 & 0.0719 & 0.0744 \\
\hline t-Stat & 11.56 & 6.30 & 6.47 & (25.56) & -10.91 & (12.15) & 11.34 & 6.47 & 6.60 \\
\hline$\alpha(1)$ & 0.1652 & 0.1099 & 0.1588 & 0.30 & 0.2387 & 0.2668 & 0.19 & 0.1812 & 0.1886 \\
\hline t-Stat & 19.68 & 9.20 & 10.08 & 27.00 & 11.19 & 12.68 & 16.22 & 8.29 & 8.77 \\
\hline$\beta(1)$ & 0.8138 & 0.833 & 0.8214 & 0.91 & 0.8807 & 0.9089 & 0.8086 & 0.8248 & 0.7723 \\
\hline t-Stat & 81.53 & 46.03 & 45.02 & 3.67 & 2.14 & 2.26 & 78.85 & 44.19 & 44.57 \\
\hline$\xi$ & & & & 1.005 & 1.0226 & 1.0157 & 0.1863 & 0.1588 & 0.1701 \\
\hline t-Stat & & - & - & 222.28 & 179.43 & 153.90 & 15.25 & 6.50 & 7.40 \\
\hline $\mathbf{v}$ & & 5.6511 & 1.3123 & & 5.3263 & 1.311 & & 5.6735 & 1.3133 \\
\hline t-Stat & & 11.12 & 40.37 & & 10.91 & 37.74 & & 11.12 & 40.27 \\
\hline Parameters & 4 & 5 & 5 & 5 & 6 & 6 & 5 & 6 & 6 \\
\hline LOGL & -4628.9 & -4503.5 & -4520.1 & -4609.3 & -4488.5 & -4506.4 & 4626.3 & -4499.8 & -4517.1 \\
\hline
\end{tabular}

Note: The parameters were estimated implementing MLE method in Matlab. This table presents the calculated t-Statistics for each parameter which is going to be compared to the tabelated value (1.956), in order to decide if the parameters are statistically significant.

"*" denotes that we obtained a parameter which is not statistically significant for a threshold of $5 \%$.

Source: Authors' own computations.

For all single state GARCH models was applied the same methodology. It is worth noting that almost all estimated parameters are significantly different from zero for a confidence level of $95 \%$ (conclusion based on the t-Student test, a two-sided test). As expected, the parameters that capture volatility's persistence recorded high values for all models. Hence, the persistence coefficient hovers around 0.8 for all distributions used for a standard GARCH model.

It is also noted that the " $v$ " parameter for the shape of distribution, in the case of GED, takes values between 1 and 2 for all models, suggesting that the modeled a distribution was one 
with thicker tails than a normal one. Moreover, looking at the kurtosis for the models for which the Student distribution was applied, we will notice that applying leptocurtic distributions is more appropriate. The obtained values were 6.63 for GARCH, 7.53 for EGARCH and 7.52 for GJR-GARCH.

Further, this paper presents the results obtained by estimating the two-states GARCH models, based on Markov-Switching methodology:

Table 2. Parameters estimated based on MRS-GARCH methodology

\begin{tabular}{|c|c|c|c|}
\hline Parameters & MRS-N & MRS-t & MRS-GED \\
\hline$\delta(1)$ & 0.0985 & 0.0457 & 0.1423 \\
\hline t-Stat & 2.25 & $1.08^{* *}$ & $1.24^{* *}$ \\
\hline$\delta(2)$ & -0.0743 & -0.0723 & -0.049 \\
\hline t-Stat & $-1.85^{*}$ & $-1.45^{* *}$ & $-0.95^{* *}$ \\
\hline$\alpha(0,1)$ & 0.2878 & 0.589 & 0.6623 \\
\hline t-Stat & 2.73 & $1.92^{*}$ & 2.54 \\
\hline$\alpha(0,2)$ & 3.0746 & 0.009 & 0.0001 \\
\hline t-Stat & 4.82 & $1.01^{* *}$ & $0.51^{* *}$ \\
\hline$\alpha(1,1)$ & 0.1563 & 0.4979 & 0.5341 \\
\hline t-Stat & 2.04 & 2.82 & 2.58 \\
\hline$\alpha(1,2)$ & 0.3844 & 0.0825 & 0.0782 \\
\hline t-Stat & 4.04 & 2.78 & 2.52 \\
\hline$\beta(1)$ & 0.4841 & 0.349 & 0.2964 \\
\hline t-Stat & 3.37 & $1.78^{*}$ & $1.33^{* *}$ \\
\hline$\beta(2)$ & 0.0353 & 0.9165 & 0.9423 \\
\hline t-Stat & $1.64^{* *}$ & 37.28 & 44.12 \\
\hline p & 0.9772 & 0.9723 & 0.9723 \\
\hline t-Stat & 88.85 & 47.91 & 36.46 \\
\hline $\mathbf{q}$ & 0.996 & 0.9823 & 0.9923 \\
\hline t-Stat & 65.30 & 122.49 & 99.23 \\
\hline $\mathrm{v}(1)$ & & 6.2342 & 1.563 \\
\hline t-Stat & & 4.65 & 19.23 \\
\hline \multicolumn{4}{|l|}{$v(2)$} \\
\hline \multicolumn{4}{|l|}{ t-Stat } \\
\hline Parameters & 10 & 12 & 11 \\
\hline LOGL & -4538.1 & -4480.7 & -4492.3 \\
\hline pi1 & $85 \%$ & $61 \%$ & $78 \%$ \\
\hline pi2 & $15 \%$ & $39 \%$ & $22 \%$ \\
\hline
\end{tabular}

Note: The parameters were estimated implementing MLE method in Matlab. This table presents the calculated t-Statistics for each parameter which is going to be compared to the tabelated value (1.956), in order to decide if the parameters are statistically significant.

"*" denotes that we have obtained a parameter which is not statistically significant for a threshold of $5 \%$.

"**" denotes that we have obtained a parameter which is not statistically significant for a threshold of $10 \%$.

Source: Authors' own computations. 
Most of the estimated parameters are statistically significant for a significance threshold of 5\%, except for parameters estimated for conditioned mean, but also the constant term for MRS-t and MRS-GED models. It should be noted that the state marked with (1) is the status for the low volatility regime, and the high volatility regime corresponds to state (2). It is very important to note that the conditional probabilities of being in state 1 and state 2 are statistically significant for all models.

PICBE | 552

It is also very interesting that the volatility persistence of the low volatility regime is lower than in the case of the high volatility regime, except for the MRS-GARCH-N model, but the persistence parameter of regime 2 is not statistically significant. If we are talking about persistence, we observe another interesting element, which is in line with literature and expectations: persistence for the high volatility regime is higher than for a standard GARCH model, and in the case of the low volatility regime is lower. This information validates that the MRS-GARCH better takes into account the cluster effect. Exception again makes the estimations for MRS-GARCH-N.

As with single state GARCH models, the "v" values indicate that distributions that better shape extreme events are better suited, distributions having thicker tails than normal distribution. It is very important to observe that the parameter for the mean equation has a negative value for the high volatility regime, suggesting a period of turbulence a period when panic can be installed. Thus, it is confirmed that periods of high volatility may be associated with downward periods, confirming that the MRS-GARCH takes into consideration the leverage effect for financial markets.

The unconditional probabilities of being in state 1 or state 2 were calculated in the last two rows of the table and they are always higher for state 1 , the low volatility regime. The explanation could be due to the low liquidity on the Bucharest Stock Exchange, the low number of participants, which may lead to a slow reaction of the local market to the drops on the foreign stock exchanges and implicitly to a lower volatility.

Further, there will be made comparisons between models using in-sample evaluation and estimated loss functions as they were presented in the previous chapter, in order to rank models based on in-sample performance. However, it should be remembered that the utility of a model is proven by the way it performs for the out-of-sample analysis, which is going to be made after the in-sample evaluation.

Various loss functions were calculated and models were hierarchized according to the obtained results. All calculations were done according to the presented methodology and the following table summarizes all obtained results: 
Table 3. The GARCH models hierarchy based on in-sample loss functions

\begin{tabular}{|c|c|c|c|c|c|c|c|c|c|c|c|c|c|c|c|c|c|c|}
\hline In-Sample & Nr. Par & AIC & Rank & BIC & Rank LOGL & Rank I & MSE1 & Rank & QLIKE & Rank & R2LOG & Rank & MAD2 & Rank I & MAD1 & Rank & HMSE & Rank \\
\hline GARCH-N & & $\begin{array}{ll}4 & 3.487\end{array}$ & 13 & 3.496 & $12-4691.56$ & 13 & 1.569 & 10 & 1.647 & 10 & 8.268 & 10 & 3.274 & 10 & 0.892 & 13 & 7.049 & 7 \\
\hline $\mathrm{ARCH}-\mathrm{t}$ & & 53.396 & 7 & 3.407 & $3-4567.78$ & 7 & 1.535 & 5 & 1.648 & 12 & 8.201 & 7 & 3.214 & 4 & 0.882 & 3 & 7.351 & 9 \\
\hline ARC & & 53.406 & 9 & 3.417 & $8-4$ & $y$ & & 8 & 1.647 & 11 & 8.188 & 4 & 3.222 & 5 & 0.882 & 2 & 7.388 & 10 \\
\hline GARCH-N & & 53.473 & 11 & 3.484 & $11-46$ & 11 & 1.491 & 3 & 1.632 & 4 & 8.275 & 12 & 3.177 & 2 & 0.887 & 7 & 6.36 & \\
\hline GARCH-t & & 63.385 & 3 & 3.398 & $1-45$ & 3 & 1.496 & 6 & 1.635 & 6 & 8.279 & 13 & 3.183 & 3 & 0.889 & 8 & 6.805 & \\
\hline GAF & & 63.396 & 6 & 3.409 & $6-45$ & 6 & 1.48 & 1 & 1.633 & 5 & 8.213 & 8 & 3.156 & 1 & 0.881 & 1 & 6.859 & $\epsilon$ \\
\hline JR-N & & 53.486 & 12 & 3.497 & $13-46$ & 12 & 1.56 & 5 & 1.645 & 7 & 8.271 & 11 & 3.272 & 9 & 0.892 & 12 & 7.239 & 8 \\
\hline$J R-t$ & & $\begin{array}{ll}6 & 3.395\end{array}$ & 5 & 3.408 & $5-45$ & 5 & 1.53 & 3 & 1.646 & 9 & 8.201 & 6 & 3.222 & 7 & 0.882 & 5 & 7.724 & 12 \\
\hline JR-GED & & 63.405 & 8 & 3.418 & $9-4579.18$ & 8 & 1.532 & 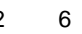 & 1.646 & 8 & 38.189 & 5 & 3.227 & 8 & 0.882 & 4 & 7.708 & 11 \\
\hline RS- & & 103.425 & 10 & 3.447 & $10-46$ & 10 & 1.497 & 4 & 1.651 & 13 & 8.225 & 9 & 3.222 & 6 & 0.892 & 11 & 8.176 & 13 \\
\hline IRS-C & & 123.381 & 2 & 3.407 & $4-45$ & 1 & 1.831 & 12 & 1.616 & 1 & 8.16 & 2 & 3.544 & 13 & 0.89 & 10 & 6.525 & 3 \\
\hline MRS-GARCH-t & & $11 \quad 3.38$ & 1 & 3.405 & $2-4540.72$ & 2 & 1.78 & 11 & 1.618 & 3 & $\begin{array}{l}38.172 \\
-172\end{array}$ & 3 & 3.489 & 11 & 0.89 & 9 & 6.474 & 2 \\
\hline MRS-GARCH-GED & & $11 \quad 3.39$ & 4 & 3.414 & $7-4553.11$ & 4 & 1.83 & 13 & 1.617 & 2 & 8.12 & 1 & 3.539 & 12 & 0.886 & 6 & 6.53 & 4 \\
\hline
\end{tabular}

Source: Authors' own computations.

The conclusions are in line with the relevant literature (Brooks and Persan (2003)) and the results obtained by Juri Marcucci (2005). Thus, there is no model to perform best for all the considered criteria, but there is a clear tendency that suggests the superiority of asymmetric models, especially EGARCH-t and EGARCH-GED, followed by the MRS-GARCH models with Student or GED distributions.

In accordance with the methodology presented at the beginning of this paper, volatility estimates will be made using the 12 models, which will be compared by different statistical loss functions. The predicted ranges are 1 day, 5 days, 10 days. It would also be interesting to see if models that are top performers for in-sample evaluation will do the same for out-of sample evaluation. The relevant literature reveals that there is often no continuity.

After estimating all models for the three intervals, each model will get one point if it is ranked first at a statistical criteria. These points will lead us to grade it in the final. This grade will be used to select the best performer model for each interval. The results for the BET index for one day, 5 and 10 will be presented below:

Table 4. One-day horizon out of sample evaluation

\begin{tabular}{|c|c|c|c|c|c|c|c|c|c|c|c|c|c|c|c|c|}
\hline Model & MSE1 & Rank & MSE2 & Rank & QLIKE & Rank & R2LOG & Rank & MAD2 & Rank & MAD1 & Rank & HMSE & Rank & SR & DA \\
\hline GARCH-N & 0.354 & 13 & 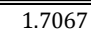 & 13 & "0.3137 & $\overline{13}$ & 1.8179 & 13 & (20.5003 & $\overline{13}$ & (20.9027 & 13 & 0.4822 & $\overline{13}$ & 0.67 & $3.2767^{* *}$ \\
\hline GARCH-t & 0.2264 & 6 & 0.7713 & 8 & 0.2023 & 4 & 1.4056 & 6 & 0.4046 & 4 & 0.6639 & 4 & 0.4111 & 4 & 0.61 & $1.8848^{*}$ \\
\hline GARCH-GED & 0.2293 & 8 & 0.7441 & 6 & 0.2259 & 11 & 1.4683 & 11 & 0.4225 & 10 & 0.6861 & 9 & 0.4353 & 11 & 0.63 & $2.6045^{* *}$ \\
\hline EGARCH-N & 0.2614 & 12 & 0.9459 & 12 & 0.2328 & 12 & 1.5157 & 12 & 0.4338 & 12 & 0.7378 & 12 & 0.4286 & 10 & 0.69 & $3.9979 * *$ \\
\hline EGARCH-t & 0.232 & 9 & 0.7744 & 9 & 0.2095 & 8 & 1.4228 & 7 & 0.4138 & 9 & 0.6841 & 8 & 0.4181 & 7 & 0.67 & $3.5677^{* *}$ \\
\hline EGARCH-GED & 0.2372 & 11 & 0.8167 & 11 & 0.2079 & 6 & 1.4235 & 8 & 0.4137 & 8 & 0.6905 & 10 & 0.4144 & 5 & 0.69 & $3.9979^{* *}$ \\
\hline GJR-N & 0.2328 & 10 & 0.7758 & 10 & 0.2226 & 10 & 1.4496 & 10 & 0.425 & 11 & 0.6968 & 11 & 0.4364 & 12 & 0.73 & $4.9005^{* *}$ \\
\hline GJR-t & 0.219 & 4 & 0.7032 & 4 & 0.208 & 7 & 1.3958 & 5 & 0.4135 & 7 & 0.67 & 7 & 0.4279 & 9 & 0.7 & $4.3453^{* *}$ \\
\hline GJR-GED & 0.2193 & 5 & 0.7145 & 5 & 0.2045 & 5 & 1.3864 & 4 & 0.4113 & 6 & 0.6683 & 5 & 0.4245 & 8 & 0.71 & $4.5236^{* *}$ \\
\hline MRS-GARCH-N & 0.1729 & 3 & 0.5384 & 3 & 0.1346 & 3 & 1.1461 & 3 & 0.3479 & 3 & 0.5479 & 3 & 0.4099 & 3 & 0.66 & $3.1885^{* *}$ \\
\hline MRS-GARCH-t & 0.1647 & 2 & 0.4953 & 1 & 0.1223 & 2 & 1.1128 & 2 & 0.3418 & 2 & 0.533 & 2 & 0.3766 & 1 & 0.66 & $3.2206^{* *}$ \\
\hline MRS-GARCH-t2 & 0.227 & 7 & 0.7553 & $\overline{7}$ & 0.2104 & $\overline{9}$ & 1.4283 & 9 & 0.4091 & 5 & 0.6685 & 6 & 0.4178 & $\overline{6}$ & 0.59 & 1.6120 \\
\hline MRS-GARCH-GED & 0.1639 & 1 & 0.5003 & 2 & 0.12 & 1 & 1.1003 & 1 & 0.3378 & 1 & 0.5279 & 1 & 0.3912 & 2 & 0.67 & $3.3927 * *$ \\
\hline
\end{tabular}

Source: Authors' own computations.

Following the one-day analysis, the MRS-GARCH-t model proves to be the best performer for all loss functions, revealing at the benefits of the two-regimes approach or the Markov-Switching methodology. 
Table 5. 5-day horizon out of sample evaluation

\begin{tabular}{|c|c|c|c|c|c|c|c|c|c|c|c|c|c|c|c|c|}
\hline Model & MSE1 & Rank & MSE2 & Rank & QLIKE & Rank & R2LOG & Rank & MAD2 & Rank & MAD1 & Rank & HMSE & Rank & SR & DA \\
\hline GARCH-N & 0.5859 & 6 & 5.3523 & 6 & 1.2622 & $\overline{6} 6$ & 2.1104 & $\overline{6} 6$ & $\begin{array}{ll}6 & 0.6698\end{array}$ & 6 & 1.8296 & $\overline{6}$ & 0.4083 & $\overline{6}$ & 0.71 & $4.6790^{* *}$ \\
\hline GARCH-t & 0.5482 & 5 & 4.8216 & 4 & 1.2467 & 5 & 2.056 & 5 & $5 \quad 0.6499$ & 5 & 1.7534 & 5 & 0.3971 & 5 & 0.71 & $4.6768^{* *}$ \\
\hline GARCH-GED & 0.5471 & 4 & 4.8855 & 5 & 1.2427 & 4 & 2.0404 & 4 & $4 \quad 0.6446$ & 4 & 1.7431 & 4 & 0.3948 & 4 & 0.72 & $4.8643^{* *}$ \\
\hline EGARCH-N & 0.4985 & 3 & 4.5006 & 3 & 1.1927 & 3 & 1.9737 & 3 & $3 \quad 0.5796$ & 3 & 1.5804 & 3 & 0.3415 & 2 & 0.74 & $5.4167^{* *}$ \\
\hline EGARCH-t & 0.4736 & 1 & 4.0795 & 1 & 1.1799 & 1 & 1.9123 & 1 & 0.562 & 1 & 1.5147 & 1 & 0.3338 & 1 & 0.74 & $5.4167^{* *}$ \\
\hline EGARCH-GED & 0.4664 & 2 & 4.0831 & 2 & 1.19 & 2 & 1.931 & 2 & 20.5756 & 2 & 1.5458 & 2 & 0.3443 & 3 & 0.74 & $5.4211^{* *}$ \\
\hline GJR-N & 0.7991 & 12 & 7.7308 & 12 & 1.3677 & 12 & 2.6102 & 12 & $2 \quad 0.8063$ & 12 & 2.2934 & 12 & 0.4748 & 12 & 0.75 & $5.6126^{* *}$ \\
\hline GJR-t & 0.7411 & 7 & 6.8925 & 7 & 1.3449 & 10 & 2.5224 & 11 & $1 \quad 0.7764$ & 10 & 2.1784 & 9 & 0.4614 & 10 & 0.73 & $5.0489^{* *}$ \\
\hline GJR-GED & 0.745 & 8 & 7.022 & 8 & 1.3435 & 9 & 2.5211 & 10 & 0.7754 & 9 & 2.1811 & 10 & 0.4596 & 9 & 0.73 & $5.2385^{* *}$ \\
\hline MRS-GARCH-N & 1.2338 & 13 & 17.281 & 13 & 1.4853 & 13 & 3.0674 & 13 & $\begin{array}{ll}3 & 0.9701\end{array}$ & 13 & 3.049 & 13 & 0.5335 & 13 & 0.69 & $4.2282^{* *}$ \\
\hline MRS-GARCH-t2 & 0.7545 & 10 & 7.432 & 10 & 1.3372 & 8 & 2.4048 & 8 & $\begin{array}{ll}8 & 0.7639\end{array}$ & 8 & 2.1737 & 8 & 0.4471 & 8 & 0.63 & $2.6941^{* *}$ \\
\hline MRS-GARCH-t & 0.7499 & 9 & 7.6026 & 11 & 1.3258 & 7 & 2.3757 & 7 & $7 \quad 0.7516$ & 7 & 2.1477 & 7 & 0.4377 & 7 & 0.63 & $2.5993^{* *}$ \\
\hline MRS-GARCH-GED & 0.7766 & 11 & 7.3506 & 9 & 1.3662 & 11 & 2.5007 & 9 & $9 \quad 0.7995$ & 11 & 2.2556 & 11 & 0.4736 & 11 & 0.64 & $3.0848^{* *}$ \\
\hline
\end{tabular}

Source: Authors' own computations.

Table 6. 10-day horizon out of sample evaluation

\begin{tabular}{|c|c|c|c|c|c|c|c|c|c|c|c|c|c|c|c|c|}
\hline Model & MSE1 & Rank & MSE2 & Rank & QLIKE & Rank & R2LOG & Rank & MAD2 & Rank & MAD1 & Rank & HMSE & Rank & SR & DA \\
\hline GARCH-N & 3.9958 & 6 & 116.92 & 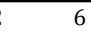 & 2.726 & 8 & 9.0764 & 8 & 1.809 & 7 & 9.4831 & 6 & 0.5458 & 8 & 0.55 & $2.6126^{* *}$ \\
\hline GARCH-t & 3.5662 & 4 & 98.493 & 4 & 2.6795 & 4 & 8.8287 & 4 & 1.699 & 4 & 8.6949 & 4 & 0.5221 & 5 & 0.57 & $2.9715^{* *}$ \\
\hline GARCH-GED & 3.6179 & 5 & 101.29 & 5 & 2.683 & 5 & 8.8525 & 5 & 1.7079 & 5 & 8.7736 & 5 & 0.5232 & 6 & 0.56 & $2.8524^{* *}$ \\
\hline EGARCH-N & 0.7933 & 2 & 10.126 & 2 & 2.2218 & 2 & 6.615 & 2 & $\quad 0.5171$ & 1 & 1.9421 & 1 & 0.1819 & 2 & 0.55 & $2.4427^{* *}$ \\
\hline EGARCH-t & 0.8279 & 1 & 10.06 & 1 & 2.2214 & 1 & 6.5939 & 1 & 0.5212 & 2 & 1.9613 & 2 & 0.183 & 3 & 0.55 & $2.4427^{* *}$ \\
\hline EGARCH-GED & 0.7879 & 3 & 11.114 & 3 & 2.2275 & 3 & 6.6286 & 3 & 30.5493 & 3 & 2.1163 & 3 & 0.1814 & 1 & 0.55 & $2.3206^{*}$ \\
\hline GJR-N & 5.0327 & 12 & 159.23 & 12 & 2.8293 & 12 & 9.8458 & 12 & 2.0481 & 12 & 11.2185 & 12 & 0.5909 & 12 & 0.52 & 2.9503* \\
\hline GJR-t & 4.5129 & 9 & 134.69 & 7 & 2.779 & 9 & 9.5818 & 10 & 1.9265 & 9 & 10.2976 & 9 & 0.5673 & 9 & 0.54 & $42.1979 *$ \\
\hline MRS-GARCH-N & 7.3716 & 13 & 311.12 & 13 & 2.9899 & 13 & 10.849 & 13 & 2.4599 & 13 & 14.8247 & 13 & 0.6521 & 13 & 0.48 & 1.4821 \\
\hline MRS-GARCH-t2 & 4.1598 & 8 & 134.76 & 8 & 2.7193 & 7 & 8.9442 & 7 & 1.814 & 8 & 9.7832 & 8 & 0.5346 & 7 & 0.59 & $3.3266^{* *}$ \\
\hline MRS-GARCH-t & 4.1156 & 7 & 137.75 & 9 & 2.6976 & 6 & 8.9269 & 6 & 1.7679 & 6 & 9.5637 & 7 & 0.5181 & 4 & 0.53 & $2.0745^{*}$ \\
\hline MRS-GARCH-GED & 4.5945 & 11 & 142.32 & 11 & 2.7914 & 11 & 9.3317 & 9 & 1.9624 & 11 & 10.6033 & 11 & 0.576 & 11 & 0.48 & $3 \quad 0.7813$ \\
\hline
\end{tabular}

Source: Authors' own computations.

Along with the loss functions, there were presented the SR (Success Ratio) and DA (Directional Accuracy) statistics. One could observe that for all models was obtained a probability of more than 50\% regarding the prediction of the direction in which the volatility will move in the next day. This statement is also supported by DA's calculation, which is significant for all models. Hence, a first step is made in demonstrating the usefulness of GARCH models and their applicability to predict volatility, especially when taking into account two volatility regimes.

For the 5 and 10 days intervals, none of the models scored better than MRS-GARCH-t did for one-day interval. This reveals the fact that the two-states approach based on Markov-Switching methodology brings added-value and that the MRS-GARCH-t could be used for estimations for short periods as one day interval.

An interesting fact to follow is the model that performs best for the 10-day interval (EGARCH-t). This result is consistent with Dacco and Satchell (1999) and the intuition based on behavioral finance theory, according to which simpler models should perform better for out-of-sample, but also for longer predictions. Their main advantage is that they are easier to implement than other models and are widely used (the more appropriate English concept would be "more parsimonious models"). Thus, for the one-day interval, the more complex MRS-GARCH-t model does better, but for longer periods of prediction, the EGARCH-t proves to be the winning solution. Also, it should be noted that asymmetric Garch models performed than standard Garch models in every situation, revealing the benefit of better taking into account the leverage effect from the financial markets.

The analysis will be continued through a part of this paper which focuses on a VaRbased risk-management functions. The indicators computed and the manner in which this was done was presented in the previous chapter related to research methodology. 


\begin{tabular}{|c|c|c|c|c|c|c|c|c|c|}
\hline \multirow{2}{*}{$\begin{array}{l}\text { Forecasting } \\
\text { (days) } \\
\text { Model }\end{array}$} & \multicolumn{3}{|c|}{1} & \multicolumn{3}{|c|}{5} & \multicolumn{3}{|c|}{10} \\
\hline & TUFF & PF(\%) & RANK & TUFF & $\mathrm{PF}(\%)$ & RANK & TUFF & PF(\%) & RANK \\
\hline GARCH-N & 3 & 4.545 & 3 & 38 & 4.688 & 3 & 36 & 1.626 & 3 \\
\hline GARCH-t & 3 & 3.03 & 2 & 38 & 3.906 & 2 & 37 & 0.815 & 2 \\
\hline GARCH-GED & 3 & 4.545 & 3 & 38 & 4.688 & 3 & 36 & 1.626 & 3 \\
\hline EGARCH-N & 3 & 3.03 & 2 & 38 & 3.906 & 2 & 33 & 10.569 & 6 \\
\hline EGARCH-t & 3 & 3.03 & 2 & 38 & 3.906 & 2 & 33 & 8.13 & 4 \\
\hline EGARCH-GED & 3 & 3.03 & 2 & 38 & 3.906 & 2 & 33 & 8.756 & 5 \\
\hline GJR-GARCH-N & 3 & 3.03 & 2 & 38 & 3.906 & 2 & 36 & 1.626 & 3 \\
\hline GJR-GARCH-t & 3 & 3.03 & 2 & 38 & 3.125 & 1 & 37 & 0.815 & 2 \\
\hline GJR-GARCH-GED & 3 & 3.03 & 2 & 38 & 3.906 & 2 & 36 & 1.626 & 3 \\
\hline MRS-GARCH-N & 3 & 3.03 & 2 & 38 & 3.906 & 2 & 37 & 0.813 & 1 \\
\hline MRS-GARCH-t & 3 & 2.273 & 1 & 38 & 3.906 & 2 & 37 & 0.815 & 2 \\
\hline MRS-GARCH-t2 & 3 & 3.03 & 2 & 38 & 3.906 & 2 & 37 & 0.903 & 3 \\
\hline MRS-GARCH-GED & 3 & 3.03 & 2 & 38 & 4.688 & 3 & 37 & 1.626 & 3 \\
\hline
\end{tabular}

Source: Authors' own computations.

In the above table, it can be noticed that the calculated time until first failure (TUFF) is 3 days, suggesting that the threshold established by the VaR (95\%) was reached for the first time after 3 days. As was done for the other analyzes, the models were hierarchized. One can notice that the best results were obtained by the models with two volatility regimes, especially by MRS-GA RCH-t. The probability of reaching VaR (95\%) was the smallest for this model, overperforming for both, the one-day and 10-day range.

Also, we can get some conclusions by interpreting the PF indicator (probability of failure), which reveals how probable is to reach the VaR calculated based on different GARCH models. This indicator highlights also that MRS-GARCH-t is the best model, because it has the lowest probability of failure (2.273\%), significantly lower than other models which are coming from behind.

\section{Conclusions}

As it was stated at the beginning of this paper, it aimed to test the accuracy of various types of single-state GARCH models, but also some forms of GARCH that depend on two volatility regimes. The objective was to identify the best model for each of the four considered prediction intervals and the results did not disappoint. Most of them were consistent with the studies in the relevant literature and they also feature distinctive elements. There elements can be justified by the specificities of the Romanian capital market (less liquid market, where companies rely mainly on financing from the banking system and less on financing through stock exchange).

The first conclusion was revealed by the in-sample analysis, observing the clear superiority of the asymmetric GARCH models (EGARCH), followed by MRS-GARCH. Given that the endpoint of developing any model is its use for forecasting, this paper went further and built an out-of-sample analysis for the same types of models. Based on this analysis, it was found that the two-state models perform better for short periods of time (one-day horizon). It is also interesting to note that each model chosen as the best for its horizons has had the errors distributed according to a Student distribution (distribution that has thicker queues - better captures extreme events). 
It is also worth noting that these results were obtained in a highly volatile environment generated by extreme and unexpected events such as the outcome for Brexit referendum in UK or the presidential election's outcome in the United States. All of these contribute to hampering the volatility estimations through Garch models which rely on historical data and historical patterns. This is one more reason to believe that the obtained results for out-of-sample evaluation are very close to reality and the two-states models perform better, but just for short periods of time.

There are a lot of ways this research could be continued and further developed, but the present results lead us to the idea that regime-switching models do improve the quality of volatility forecasts. It is unanimously accepted that there is no volatility forecasting model that predicts better in any situation, but the multi-state models can adapt to different market situations and can lead to better results. Hence, adapting the actual methodology for three-state or four-state models with different error distributions could bring value-added further and could represent a very important contribution to the present literature.

\section{References}

Alexander, C. Lazar, E (2009), Modelling Regime-Specific Stock Price Volatility, Oxford Bulletin of Economics and Statistics, volume 71 (6), 761-797.

Bollerslev, T. (1986), Generalized Autoregressive Conditional Heteroskedasticity, Journal of Econometrics, 31, 307-327.

Brooks, C., \& Persand, G. (2003). Volatility forecasting for risk management. Journal of forecasting, 22(1), 1-22.

Cai, J. (1994), A Markov Model of Unconditional Variance in ARCH, Journal of Business and Economic Statistics,12, 309-316.

Dacco, R., \& Satchell, S. (1999). Why do regime-switching models forecast so badly?. Journal of forecasting, 18(1), 1-16.

Glosten, L. R., Jagannathan, R., \& Runkle, D. E. (1993). On the relation between the expected value and the volatility of the nominal excess return on stocks. The journal of finance, 48(5), 1779-1801.

Gray, S. (1996), Modeling the Conditional Distribution of Interest Rates as a RegimeSwitching Process, Journal of Econometrics, 42, 27-67.

Greene W. (2002), Econometric Analysis, Prentice Hall, 4th Edition.

Hamilton, J.D, R. Susmel (1994), Autoregressive Conditional Heteroskedasticity and Changes in Regime, Journal of Econometrics, 64, 307-333.

Klaassen, F. (2002), Improving GARCH Volatility Forecasts, Empirical Economics, 27 (2), 363-394.

Koopman, S. J., Jungbacker, B., \& Hol, E. (2005). Forecasting daily variability of the S\&P 100 stock index using historical, realised and implied volatility measurements. Journal of Empirical Finance, 12(3), 445-475.

Marcucci, J. (2005), Forecasting Stock Market Volatility with Regime-Switching GARCH Models, Studies in Nonlinear Dynamics \& Econometrics, vol. 9, 1-55.

Nelson, D.B (1991), Conditional Heteroskedasticity in Asset Returns: A New Approach, Econometrica, 59 (2), 347-370.

Pagan, A. R., \& Schwert, G. W. (1990). Alternative models for conditional stock volatility. Journal of econometrics, 45(1-2), 267-290. 